\title{
Lower High-Density Lipoprotein Cholesterol Concentration Is Independently Associated with Greater Future Accumulation of Intra-Abdominal Fat
}

\author{
Sun Ok Song ${ }^{1,2,3}$, You-Cheol Hwang ${ }^{4}$, Han Uk Ryu ${ }^{5}$, Steven E. Kahn ${ }^{6,7}$, Donna L. Leonetti ${ }^{8}$, Wilfred Y. Fujimoto ${ }^{7}$, \\ Edward J. Boyko ${ }^{1,2}$ \\ ${ }^{1}$ Epidemiologic Research and Information Center, VA Puget Sound Health Care System; ${ }^{2}$ Department of Medicine, University \\ of Washington School of Medicine, Seattle, WA, USA; ${ }^{3}$ Division of Endocrinology and Metabolism, Department of Internal \\ Medicine, National Health Insurance Service Ilsan Hospital, Goyang; ${ }^{4}$ Division of Endocrinology and Metabolism, Department \\ of Medicine, Kyung Hee University Hospital at Gangdong, Kyung Hee University School of Medicine, Seoul; ${ }^{5}$ Department of \\ Neurology, Jeonbuk National University Medical School, Jeonju, Korea; ${ }^{6}$ Hospital and Specialty Medicine Service, VA Puget \\ Sound Health Care System; ${ }^{7}$ Division of Metabolism, Endocrinology and Nutrition, Department of Medicine, University of \\ Washington School of Medicine; ${ }^{8}$ Department of Anthropology, University of Washington, Seattle, WA, USA
}

Background: Both intra-abdominal fat (IAF) and high-density lipoprotein cholesterol (HDL-C) are known to be associated with cardiometabolic health. We evaluated whether the accumulation of computed tomography (CT)-measured IAF over 5 years was related to baseline HDL-C concentration in a prospective cohort study.

Methods: All participants were Japanese-Americans between the ages of 34 and 74 years. Plasma HDL-C concentration and CT measurements of IAF, abdominal subcutaneous fat (SCF), and thigh SCF cross-sectional areas were assessed at baseline and at 5-year follow-up visits.

Results: A total of 397 subjects without diabetes were included. The mean \pm standard deviation HDL-C concentration was 51.6 \pm 13.0 $\mathrm{mg} / \mathrm{dL}$ in men and $66.0 \pm 17.0 \mathrm{mg} / \mathrm{dL}$ in women, and the IAF was $91.9 \pm 48.4 \mathrm{~cm}^{2}$ in men and $63.1 \pm 39.5 \mathrm{~cm}^{2}$ in women. The baseline plasma concentration of HDL-C was inversely associated with the change in IAF over 5 years using multivariable regression analysis with adjustment for age, sex, family history of diabetes, weight change over 5 years, and baseline measurements of body mass index, IAF, abdominal SCF, abdominal circumference, thigh SCF, and homeostatic model assessment for insulin resistance.

Conclusion: These results demonstrate that HDL-C concentration significantly predicts future accumulation of IAF over 5 years independent of age, sex, insulin sensitivity, and body composition in Japanese-American men and women without diabetes.

Keywords: Intra-abdominal fat; Cholesterol, HDL; Epidemiology; Asian Americans

\section{INTRODUCTION}

Body fat distribution is accepted as an important risk factor for

Received: 26 May 2021, Revised: 12 July 2021, Accepted: 15 July 2021

Corresponding author: Sun Ok Song

Division of Endocrinology and Metabolism, Department of Internal Medicine, National Health Insurance Service Ilsan Hospital, 100 Ilsan-ro, Ilsandong-gu, Goyang 10444, Korea

Tel: +82-31-900-3470, Fax: +82-31-900-0519, E-mail: songsun7777@gmail.com

developing cardiovascular disease (CVD) in the general population in addition to the overall level of adiposity [1,2]. All body fat is not the same regarding the risk of cardiometabolic condi-

Copyright $\odot 2021$ Korean Endocrine Society

This is an Open Access article distributed under the terms of the Creative Commons Attribution Non-Commercial License (https://creativecommons.org/ licenses/by-nc/4.0/) which permits unrestricted non-commercial use, distribution, and reproduction in any medium, provided the original work is properly cited. 
tions. Visceral adipose tissue (intra-abdominal fat [IAF]) has emerged as the most pathogenic fat depot and has been reported to be a potential causal factor in the development of diabetes, hypertension, lower insulin sensitivity, dyslipidemia, coronary heart disease, and metabolic syndrome [3-9]. IAF accumulation can increase the risk of cardiovascular complications more strongly than other fat depots $[5,6,10,11]$.

It has been reported that a higher high-density lipoprotein cholesterol (HDL-C) level can decrease the risk of CVD [12]. A low level of HDL-C was identified as a major risk factor for coronary artery disease (CAD) in the Framingham study. Furthermore, in that cohort study, HDL-C levels showed a stronger association with the incidence of CAD than low-density lipoprotein cholesterol (LDL-C) levels [13,14], leading to the inclusion of HDL-C as a key component of the Framingham risk equation. Subsequently, multiple studies have revealed an inverse correlation between HDL-C and CVD risk in humans [1518]. Moreover, HDL-C is strongly associated with body composition, with a significant inverse relationship between body fat percentage and HDL-C concentration [19,20]. Further research on overall and regional adiposity demonstrated that HDL-C concentrations were correlated with more types of anthropometric measurements (e.g., body mass index [BMI], waist and hip circumference, waist-to-hip ratio, and body fat percentage) than other lipid parameters $[21,22]$. In particular, it has been reported that there is a significant and inverse correlation between HDL$\mathrm{C}$ and IAF area in men and women [6,9]. The temporal relationship between fat accumulation and HDL-C, however, is not well understood. While both IAF [5,6,9,11] and HDL-C [15-18] have been found to be inversely correlated in cross-sectional studies, whether low HDL-C predates IAF accumulation has not been previously explored to our knowledge [6,9]. Research investigating this question would require a longitudinal assessment of changes in IAF or HDL following baseline measurements. Therefore, we evaluated whether baseline HDL-C concentration was associated with changes in computed tomography (CT)-measured IAF area over 5 years in the prospective Japanese-American Community Diabetes Study.

\section{METHODS}

\section{Study population and design}

The study population was composed of second- (Nisei) and third-generation (Sansei) Japanese-Americans of 100\% Japanese ancestry (men and women) enrolled in the Japanese-American Community Diabetes Study. We have previously published a detailed characterization regarding the selection and recruitment criteria of this study population $[23,24]$. The original cohort sample size of 658 was determined based on the goal of estimating type 2 diabetes prevalence and incidence and not for testing the hypothesis described in this paper. Among the 658 subjects of the original cohort, we excluded 113 subjects who did not complete follow-up examinations or CT scans at baseline or 5-year follow-up. Moreover, 148 subjects were excluded from this study because they had fasting plasma glucose levels equal to or higher than $126 \mathrm{mg} / \mathrm{dL}$, plasma glucose at 2 hours after a 75 -g oral glucose tolerance test $\geq 200 \mathrm{mg} / \mathrm{dL}$, or were treated with oral hypoglycemic agents or insulin at baseline or at a 5-year visit. As a result, this study analyzed 397 subjects without diabetes (207 men and 190 women) between 34 and 75 years old (Supplemental Fig. S1 for the participant flowchart). This protocol was approved by the Human Subjects Review Committee at the University of Washington (Institutional Review Board number 35081). All participants signed written informed consent. All evaluations were performed according to the principles of the Declaration of Helsinki.

\section{Clinical and laboratory examination}

All examinations were carried out at the General Clinical Research Center, University of Washington Medical Center. A complete physical examination was conducted and medical history and lifestyle factors (e.g., physical activity, alcohol consumption, and smoking) were evaluated using a standardized survey at baseline. Smoking was categorized into three groups (i.e., current smoking at the time of the examination; past smoking prior to the time of the examination but currently not smoking; and never smoked). We used the Paffenbarger physical activity index questionnaire to estimate physical activity levels (usual kilocalories spent weekly) [25]. Alcohol consumption was measured in grams of alcohol per day [25]. A positive family history of diabetes indicated that any first-degree relative had diabetes. BMI was calculated by dividing body weight $(\mathrm{kg})$ by the height squared $\left(\mathrm{m}^{2}\right)$. Waist circumference was measured using a tape measure at the position of the umbilicus, generally located between L4 and L5 [26]. Biochemical indicators were measured as reported previously [27]. All blood samples were collected after participants fasted for 10 hours overnight. The hexokinase method was employed to measure plasma glucose using an autoanalyzer (University of Washington, Department of Laboratory Medicine, Seattle, WA, USA). Plasma insulin was analyzed using a radioimmunoassay (Immunoassay Core, Diabetes Research Center, University of Washington, Seattle, 
WA, USA). To analyze insulin sensitivity, this study used the homeostasis model assessment of insulin resistance (HOMAIR) index, which was calculated from fasting plasma glucose and insulin concentrations: (insulin [IU/mL] multiplied by plasma glucose level [mg/dL])/405 [28]. The modified procedures of the Lipid Research Clinics were used to measure lipid and lipoprotein concentrations (Northwest Lipid Research Laboratory, University of Washington, Seattle, WA, USA). The crosssectional fat area $\left(\mathrm{cm}^{2}\right)$ of visceral IAF and abdominal subcutaneous fat (SCF) were analyzed using single 10-mm CT scan slices at the level of the umbilicus. The point midway between the greater trochanter and the superior margin of the patella was used for CT measurements of thigh fat area. CT scan images were analyzed by density contour software (Standard GE 8800 computer software, General Electric Co, Milwaukee, WI, USA). Fat was identified at the attenuation range of -250 to -50 Hounsfield units [29]. The changes $(\Delta)$ in IAF and weight were calculated by subtracting baseline values from the values at 5 -year follow-up.

\section{Statistical analyses}

Continuous variables are displayed as mean \pm standard deviation, and categorical variables as numbers or percentages. Differences in continuous variables were assessed using the $t$ test with unequal variance or non-parametric tests. The differences in the frequencies of categorical data were compared using the chi-square test. We estimated unadjusted linear regression coefficients between temporal changes in IAF from baseline to 5 years (IAF at 5 years minus baseline IAF; $\triangle \mathrm{IAF}$ ) as the dependent continuous variable, and anthropometric variables, metabolic variables, and body composition measures as independent variables. We conducted bivariable analysis and multiple regression analysis to evaluate the independent relationships between $\triangle \mathrm{IAF}$ and HDL-C concentration while considering various covariates (e.g., age, sex, BMI, insulin resistance, regional fat depots, family history of diabetes, alcohol consumption, physical activities, and smoking). Possible interactions between sex and HDL-C in connection with $\triangle \mathrm{IAF}$ were examined by adding first-order interaction terms into the regression model. All statistical analyses were carried out using Stata/MP version 15.1 (StataCorp, College Station, TX, USA). Statistical significance was determined at $P<0.05$ for a two-sided test. The data for this study are not available in a public repository but are potentially available to investigators through contact with the senior author of this paper.

\section{RESULTS}

Table 1 shows the clinical and laboratory characteristics of the subjects. This analysis included 397 participants without diabetes (207 [52.14\%] men and 190 [47.86\%] women); their mean age was $51.12 \pm 11.79$ years, and their BMI was $24.04 \pm 3.15 \mathrm{~kg} / \mathrm{m}^{2}$. The mean concentration of HDL-C in men was lower than that in women, as expected. Conversely, also as expected, the mean IAF was greater in men in women. The 5-year follow-up compared to baseline showed higher mean values for BMI, abdomen circumference, glucose levels, insulin, HOMA-IR, triglycerides, IAF, abdominal SCF, and thigh SCF, while lower mean values were seen for total cholesterol, LDL-C, and HDL-C.

The univariate analysis of characteristics associated with 5 -year $\triangle \mathrm{IAF}$ showed significant positive associations with baseline thigh SCF and change in body weight from baseline to 5 years ( $\Delta$ weight change) and negative associations with age and baseline IAF (Table 2). Sex, family history of diabetes, BMI, alcohol consumption, physical activity, smoking, abdominal SCF, and HDL-C and LDL-C levels were not significantly associated with $\triangle \mathrm{IAF}$.

Next, bivariable analyses (Table 3) were performed to examine whether other covariates confounded the relationship between baseline HDL-C concentration and 5-year $\triangle \mathrm{IAF}$ because univariate analysis revealed that HDL-C and 5-year $\triangle \mathrm{IAF}$ were not significantly correlated. It was found that HDL-C and 5-year $\triangle \mathrm{IAF}$ were significantly and negatively correlated when baseline IAF was adjusted. Adjustment for other variables shown in Table 3 did not result in HDL-C becoming a significant predictor of 5-year $\triangle \mathrm{IAF}$.

Multivariable analyses were carried out to decide whether HDL-C concentration could predict 5-year $\triangle \mathrm{IAF}$ independently (Table 4). In the first model (model 1), which included age, sex, family history of diabetes, $\Delta$ weight change, and baseline BMI, IAF, abdominal SCF, abdomen circumference, thigh SCF, 2-hour glucose, and HOMA-IR, HDL-C concentration was significantly and inversely related to $\triangle \mathrm{IAF}$. Age and $\Delta$ weight change showed significant positive associations, while baseline IAF showed a significant negative association with $\triangle I A F$. Further adjustment of model 1 for alcohol consumption (model 2), alcohol consumption and physical activity (model 3), and alcohol consumption, physical activity, and smoking (model 4) yielded similar results. Age and $\Delta$ weight change showed significant positive associations with $\triangle \mathrm{IAF}$, while baseline IAF was negatively associated in every model. In these models, HDL-C and 5-year $\triangle \mathrm{IAF}$ continued to show a significant and negative 
Table 1. Baseline Demographic and Clinical Characteristics of Study Subjects

\begin{tabular}{|c|c|c|c|}
\hline Characteristic & Total $(n=397)$ & Male $(n=207)$ & Female $(n=190)$ \\
\hline \multicolumn{4}{|l|}{ Baseline } \\
\hline Age, yr & $51.1 \pm 11.8$ & $51.1 \pm 11.8$ & $51.1 \pm 11.8$ \\
\hline Family history of diabetes & $135(34.0)$ & $62(30.0)$ & $73(38.4)$ \\
\hline Body mass index, $\mathrm{kg} / \mathrm{m}^{2}$ & $24.1 \pm 3.2$ & $25.1 \pm 2.8$ & $22.9 \pm 3.1$ \\
\hline Abdominal circumference, $\mathrm{cm}$ & $85.5 \pm 8.6$ & $87.6 \pm 7.7$ & $83.3 \pm 9.0$ \\
\hline Alcohol consumption, g/day & $5.2 \pm 11.1$ & $8.1 \pm 13.7$ & $2.0 \pm 5.6$ \\
\hline Current smoking & $56(14.1)$ & $32(15.5)$ & $24(12.6)$ \\
\hline Physical activity, kcal/week & $2,751.2 \pm 1,941.2$ & $3,034.3 \pm 2,196.1$ & $2,421.8 \pm 1,535.7$ \\
\hline Systolic blood pressure, $\mathrm{mm} \mathrm{Hg}$ & $127.2 \pm 17.3$ & $130.4 \pm 17.4$ & $123.7 \pm 16.5$ \\
\hline Diastolic blood pressure, $\mathrm{mm} \mathrm{Hg}$ & $76.2 \pm 9.4$ & $78.6 \pm 8.9$ & $73.6 \pm 9.3$ \\
\hline Baseline fasting glucose, $\mathrm{mg} / \mathrm{dL}$ & $92.5 \pm 10.1$ & $94.9 \pm 10.6$ & $89.7 \pm 8.8$ \\
\hline Baseline 2-hour OGTT glucose, mg/dL & $126.6 \pm 29.5$ & $126.5 \pm 31.0$ & $126.7 \pm 27.9$ \\
\hline Fasting plasma insulin, $\mathrm{mU} / \mathrm{mL}$ & $13.4 \pm 8.1$ & $12.3 \pm 6.7$ & $14.6 \pm 9.2$ \\
\hline HOMA-IR & $3.0 \pm 1.7$ & $2.9 \pm 1.7$ & $3.2 \pm 1.8$ \\
\hline Total cholesterol, mg/dL & $223.7 \pm 41.4$ & $227.2 \pm 42.0$ & $219.9 \pm 40.4$ \\
\hline Triglyceride, $\mathrm{mg} / \mathrm{dL}$ & $134.2 \pm 104.0$ & $153.4 \pm 113.9$ & $113.4 \pm 87.6$ \\
\hline LDL-C, mg/dL & $139.0 \pm 36.6$ & $145.7 \pm 38.0$ & $131.7 \pm 33.5$ \\
\hline HDL-C, mg/dL & $58.5 \pm 16.7$ & $51.6 \pm 13.0$ & $66.0 \pm 17.0$ \\
\hline Baseline IAF, $\mathrm{cm}^{2}$ & $78.3 \pm 46.7$ & $91.9 \pm 48.4$ & $63.1 \pm 39.5$ \\
\hline Baseline abdominal SCF, $\mathrm{cm}^{2}$ & $156.5 \pm 77.3$ & $136.7 \pm 66.2$ & $178.5 \pm 82.9$ \\
\hline Baseline thigh SCF, $\mathrm{cm}^{2}$ & $65.0 \pm 31.5$ & $46.0 \pm 18.2$ & $86.3 \pm 29.5$ \\
\hline \multicolumn{4}{|l|}{ Follow-up at 5 years } \\
\hline Body mass index, $\mathrm{kg} / \mathrm{m}^{2}$ & $24.7 \pm 3.4$ & $25.4 \pm 3.0$ & $23.8 \pm 3.6$ \\
\hline Abdominal circumference, $\mathrm{cm}$ & $89.4 \pm 47.1$ & $89.3 \pm 7.9$ & $89.5 \pm 67.9$ \\
\hline Baseline fasting glucose, $\mathrm{mg} / \mathrm{dL}$ & $97.0 \pm 8.6$ & $97.4 \pm 8.8$ & $96.5 \pm 8.4$ \\
\hline Baseline 2-hour OGTT glucose, mg/dL & $138.6 \pm 29.0$ & $133.4 \pm 28.4$ & $144.2 \pm 28.7$ \\
\hline Fasting plasma insulin, $\mathrm{mU} / \mathrm{mL}$ & $15.5 \pm 9.1$ & $16.7 \pm 10.3$ & $14.3 \pm 7.4$ \\
\hline HOMA-IR & $3.8 \pm 2.3$ & $4.0 \pm 2.6$ & $3.5 \pm 2.0$ \\
\hline Total cholesterol, mg/dL & $212.9 \pm 36.0$ & $215.2 \pm 34.7$ & $210.4 \pm 37.2$ \\
\hline Triglyceride, $\mathrm{mg} / \mathrm{dL}$ & $144.4 \pm 106.9$ & $152.5 \pm 110.0$ & $135.6 \pm 103.0$ \\
\hline LDL-C, mg/dL & $129.7 \pm 35.9$ & $136.5 \pm 34.8$ & $122.4 \pm 35.6$ \\
\hline HDL-C, mg/dL & $55.0 \pm 15.7$ & $49.9 \pm 12.9$ & $60.5 \pm 16.6$ \\
\hline IAF, $\mathrm{cm}^{2}$ & $87.6 \pm 44.6$ & $98.4 \pm 45.1$ & $75.6 \pm 41.0$ \\
\hline Abdominal SCF, $\mathrm{cm}^{2}$ & $174.7 \pm 86.7$ & $150.8 \pm 71.6$ & $201.4 \pm 94.2$ \\
\hline Thigh SCF, $\mathrm{cm}^{2}$ & $65.8 \pm 36.0$ & $43.7 \pm 17.5$ & $90.9 \pm 35.0$ \\
\hline
\end{tabular}

Values are expressed as mean \pm standard deviation or number (\%).

OGTT, oral glucose tolerance test; HOMA-IR, homeostasis model assessment of insulin resistance; LDL-C, low-density lipoprotein cholesterol; HDL$\mathrm{C}$, high-density lipoprotein cholesterol; IAF, intra-abdominal fat; SCF, subcutaneous fat.

relationship. Table 5 shows the results of the multivariable models in Table 4 using Z-transformed covariate data to permit comparisons of strengths of the association with $\triangle \mathrm{IAF}$. These results demonstrate that HDL-C had a similar strength of asso- ciation as age in predicting $\triangle \mathrm{IAF}$, with baseline IAF and change in weight over 5 years demonstrating the strongest associations. There were 45 post-menopausal women in our population. We performed an adjustment for menopause in the models in Table 
Table 2. Univariate Regression Analysis of Change in IAF from Baseline to 5 Years in Relation to Measurements of Lifestyle, Demographic, Body Fat, and Metabolic Characteristics

\begin{tabular}{|c|c|c|c|}
\hline Change in IAF from baseline to 5 years & Coefficient & $95 \% \mathrm{CI}$ & $P$ value \\
\hline Age & -0.46364 & -0.69859 to -0.22868 & $<0.001$ \\
\hline Female & 4.63139 & -1.01088 to 10.27365 & 0.107 \\
\hline Family history of diabetes & -1.20698 & -7.14613 to 4.73217 & 0.690 \\
\hline Body mass index & -0.78305 & -1.65870 to 0.09260 & 0.080 \\
\hline Alcohol consumption & -0.05434 & -0.31142 to 0.20274 & 0.678 \\
\hline Physical activity & -0.00004 & -0.00150 to 0.00141 & 0.955 \\
\hline Current smoker & -1.52412 & -10.10930 to 7.06107 & 0.727 \\
\hline Baseline IAF & -0.20951 & -0.26483 to -0.15419 & $<0.001$ \\
\hline Baseline abdominal SCF & -0.01043 & -0.04665 to 0.02580 & 0.572 \\
\hline Baseline thigh SCF & 0.09064 & 0.00173 to 0.17956 & 0.046 \\
\hline Change in body weight from baseline to 5 years & 4.15054 & 3.46111 to 4.83997 & $<0.001$ \\
\hline Baseline fasting OGTT BLG & -4.32146 & -9.37317 to 0.73025 & 0.093 \\
\hline Baseline 2-hour OGTT BLG & -0.59917 & -2.29298 to 1.09463 & 0.487 \\
\hline Total cholesterol & -1.53935 & -4.20926 to 1.13057 & 0.258 \\
\hline Triglyceride & -1.12349 & -3.53585 to 1.28887 & 0.360 \\
\hline LDL-C & -1.29330 & -4.29901 to 1.71241 & 0.398 \\
\hline HDL-C & 2.64755 & -3.90249 to 9.19759 & 0.427 \\
\hline Baseline fasting insulin & -0.00926 & -0.06911 to 0.05058 & 0.761 \\
\hline HOMA-IR & -0.31140 & -1.96898 to 1.34617 & 0.712 \\
\hline
\end{tabular}

4 and obtained nearly identical and statistically significant results for the association between HDL-C and $\triangle \mathrm{IAF}$ (data not shown).

Since both IAF and HDL-C vary by sex, this study examined the relationship between HDL-C and $\triangle \mathrm{IAF}$, which can be affected by sex, by adding a sex $\times$ HDL-C interaction term to the multivariable models (Table 4). No significant interaction was found between HDL-C and sex when this term was added (data not shown). Few subjects were taking lipid-lowering medications during the course of this research. The results shown in Table 4 were similar when we repeated models $1-4$ after excluding the eight participants taking lipid-lowering medications (data not shown).

\section{DISCUSSION}

This study prospectively evaluated Japanese-American men and women without diabetes, finding that HDL-C concentration and future accumulation of IAF were negatively related over 5 years and that this association was independent of age, sex, insulin sensitivity, glycemia, body composition, smoking and lifestyle factors potentially affecting HDL-C levels such as alcohol consumption and physical activity. These results indicate that greater accumulation of IAF occurred in the subjects with lower baseline HDL-C concentrations in this population.

Previous cross-sectional studies have revealed that IAF and HDL-C concentration are related. The inverse relationship between IAF and HDL-C concentration has also been reported in other populations showing a variety of characteristics, including obese, non-obese, dyslipidemic, and non-diabetic subjects [3034]. A negative relationship between IAF and HDL-C concentration was also reported in a previous cross-sectional study conducted in this Japanese-American cohort [3]. Moreover, it was also reported that regular endurance exercise helped to increase low HDL-C levels with an accompanying decrease in abdominal obesity, demonstrating that changes in HDL-C concentrations are associated with changes in abdominal obesity in response to an intervention [35].

Interestingly, the appearance of an association between HLD$\mathrm{C}$ and $\triangle \mathrm{IAF}$ depended on adjustment for covariates in the re- 
Table 3. Bivariable Analysis of the Prediction of Change in IAF in Relation to Measurements of Lifestyle, Demographic, Body Fat, and Metabolic Characteristics

\begin{tabular}{lcc}
\hline Model & HDL-C coefficient & $P$ value \\
\hline HDL-C & 2.64755 & 0.427 \\
HDL-C, Age & 2.02412 & 0.537 \\
HDL-C, Female & 0.33474 & 0.928 \\
HDL-C, Family history & 2.58178 & 0.440 \\
HDL-C, Body mass index & 0.22131 & 0.952 \\
HDL-C, Alcohol & 2.81306 & 0.402 \\
HDL-C, Physical activity & 2.66800 & 0.425 \\
HDL-C, Current smoking & 2.73997 & 0.426 \\
HDL-C, Baseline IAF & -11.34154 & 0.001 \\
HDL-C, Baseline abdominal SCF & 2.46807 & 0.462 \\
HDL-C, Baseline thigh SCF & 1.24987 & 0.714 \\
HDL-C, Weight change for 5 years & -1.10593 & 0.702 \\
HDL-C, Fasting glucose & 1.34272 & 0.696 \\
HDL-C, Postprandial glucose & 2.53154 & 0.449 \\
HDL-C, Total cholesterol & 2.76191 & 0.408 \\
HDL-C, Triglyceride & 1.58845 & 0.672 \\
HDL-C, LDL-C & 2.29767 & 0.495 \\
HDL-C, Fasting insulin & 2.55711 & 0.460 \\
HDL-C, HOMA-IR & 2.49944 & 0.473 \\
\hline
\end{tabular}

IAF, intra-abdominal fat; HDL-C, high-density lipoprotein cholesterol; SCF, subcutaneous fat; LDL-C, low-density lipoprotein cholesterol; HOMA-IR, homeostasis model assessment of insulin resistance.

gression analysis. While we consistently observed associations in the same direction between $\triangle \mathrm{IAF}$ with change in weight and baseline IAF in both unadjusted and adjusted analyses, the relationship between $\triangle \mathrm{IAF}$ and HDL-C was not observed until baseline IAF was adjusted. It has been reported that body weight changes are related to HDL-C as well as IAF, with an IAF increase associated with an HDL decrease [20]. We observed a negative association between baseline IAF and $\triangle \mathrm{IAF}$, such that greater baseline IAF predicted less IAF accumulation over 5 years. Additionally, greater IAF at baseline was related to lower baseline HDL-C. Owing to this strong relationship between baseline IAF and HDL-C, baseline IAF was adjusted to control confounding and permitted identification of the negative relationship between HDL-C and $\triangle \mathrm{IAF}$.

There are several possible mechanisms whereby high HDL-C concentration may prevent accumulation of IAF. HDL-C is generally accepted as a friendly scavenger that promotes cholesterol efflux from peripheral cells and transfers the obtained cholester- ol to the liver for excretion, which constitutes the main reverse cholesterol transport channel [36]. Given this finding, HDL-C might lessen lipid accumulation in adipocytes [37], which could possibly reduce accumulation of IAF. HDL-C contributes to modulating body fat content by directly advancing catecholamine-elicited, but not basal lipolysis, possibly through a receptor-mediated mechanism with apolipoprotein A-I (ApoA-I) [38]. Decreased levels of circulating HDL-C and ApoA-I, its major protein, may contribute directly to causing or maintaining the obese condition [38]. In addition, HDL-C could serve as a marker for metabolic activity. Metabolically healthy obese subjects had 21\% higher HDL-C concentrations and a resting metabolic rate per BMI unit that was $25 \%$ higher than metabolically unhealthy obese individuals [39].

In addition, human clinical and animal studies have reported that HDL-C has direct impacts on adipocyte metabolism. Serum adiponectin is also positively associated with HDL-C [40]. Moreover, a longitudinal study from our Japanese-American population showed that low plasma adiponectin concentration was a valid independent predictor for abdominal visceral fat accumulation [41]. Finally, higher HDL-C due to ApoA-I transfer influences the gene expression associated with metabolism of fatty acid in adipose tissues and potently decreases triglyceride concentration. Furthermore, HDL-C is positively associated with plasma adiponectin concentration and adiponectin expression in adipocytes in vivo.

The importance of this study includes the fact that direct fat measurements were made using CT scans, enabling an accurate assessment of fat depots in the regions of interest and permitting an evaluation of change over time. As far as we are aware, this study is the first effort to examine the relationship between HDL-C and change in IAF. The results of this study imply that HDL-C concentration is a readily available marker for predicting IAF accumulation as well as CVD risk.

Nevertheless, there are several limitations of this study. First, because the subjects in this study were exclusively JapaneseAmericans, these results might not be applicable to other ethnic groups. Secondly, the present findings arise from an observational study design, precluding conclusions about causality. Additionally, due to the nature of all observational research, although all known covariates were adjusted, unknowable factors could have caused confounding in the relationship between the concentration of serum HDL-C and adiposity. This study also could not evaluate the functional states of HDL-C or further examine the structure of HDL-C. Finally, physical activity meeting or exceeding a certain level of caloric expenditure should be 
Table 4. Multivariable Linear Regression Analysis of the Prediction of Change in IAF in Relation to Measurements of Lifestyle, Demographic, Body Fat, and Metabolic Characteristics

\begin{tabular}{|c|c|c|c|c|c|c|c|c|}
\hline \multirow{2}{*}{ Change in body IAF from baseline to 5 years } & \multicolumn{2}{|c|}{ Model 1} & \multicolumn{2}{|c|}{ Model 2} & \multicolumn{2}{|c|}{ Model 3} & \multicolumn{2}{|c|}{ Model 4} \\
\hline & $\beta$ & $P$ value & $\beta$ & $P$ value & $\beta$ & $P$ value & $\beta$ & $P$ value \\
\hline HDL-C & -12.6953 & $<0.001$ & -13.5757 & $<0.001$ & -13.0597 & $<0.001$ & -13.2910 & $<0.001$ \\
\hline Age & 0.4800 & $<0.001$ & 0.4877 & $<0.001$ & 0.4794 & $<0.001$ & 0.4664 & $<0.001$ \\
\hline Female & -4.5793 & 0.2900 & -3.6519 & 0.4080 & -3.4003 & 0.4410 & -3.1102 & 0.4820 \\
\hline Family history of diabetes & -0.5470 & 0.8260 & -0.4996 & 0.8400 & -0.3766 & 0.8790 & -0.6020 & 0.8090 \\
\hline Body mass index & 0.5963 & 0.4120 & 0.6191 & 0.3950 & 0.8393 & 0.2590 & 0.8036 & 0.2840 \\
\hline Baseline IAF & -0.3412 & $<0.001$ & -0.3437 & $<0.001$ & -0.3494 & $<0.001$ & -0.3478 & $<0.001$ \\
\hline Baseline abdominal SCF & 0.0177 & 0.5120 & 0.0175 & 0.5150 & 0.0146 & 0.5870 & 0.0144 & 0.5960 \\
\hline Baseline thigh SCF & 0.0390 & 0.5100 & 0.0415 & 0.4840 & 0.0266 & 0.6570 & 0.0292 & 0.6270 \\
\hline Change in body weight from baseline to 5 years & 3.9405 & $<0.001$ & 3.9427 & $<0.001$ & 3.9803 & $<0.001$ & 3.9656 & $<0.001$ \\
\hline Baseline 2-hour OGTT BLG & 1.5661 & 0.0380 & 1.6152 & 0.0330 & 1.5600 & 0.0390 & 1.4709 & 0.0530 \\
\hline HOMA-IR & 0.4007 & 0.6250 & 0.3709 & 0.6510 & 0.2945 & 0.7200 & 0.3152 & 0.7010 \\
\hline Alcohol consumption & & & 0.1177 & 0.2970 & 0.1145 & 0.3100 & 0.1072 & 0.3570 \\
\hline Physical activity & & & & & -0.0009 & 0.1600 & -0.0009 & 0.1470 \\
\hline Current smoker & & & & & & & -2.4761 & 0.5050 \\
\hline R squared & & 0.4004 & & 0.4022 & & 0.4054 & & 0.4074 \\
\hline
\end{tabular}

IAF, intra-abdominal fat; HDL-C, high-density lipoprotein cholesterol; SCF, subcutaneous fat; OGTT, oral glucose tolerance test; BLG, blood glucose; HOMA-IR, homeostasis model assessment of insulin resistance.

Table 5. Multivariable Linear Regression Analysis of the Prediction of Change in IAF in Relation to Measurements of Lifestyle, Demographic, Body Fat, and Metabolic Characteristics Using Z-Transformed Data for Covariates

\begin{tabular}{|c|c|c|c|c|c|c|c|c|}
\hline \multirow{2}{*}{ Change in body IAF from baseline to 5 years } & \multicolumn{2}{|c|}{ Model 1} & \multicolumn{2}{|c|}{ Model 2} & \multicolumn{2}{|c|}{ Model 3} & \multicolumn{2}{|c|}{ Model 4} \\
\hline & $\beta$ & $P$ value & $\beta$ & $P$ value & $\beta$ & $P$ value & $\beta$ & $P$ value \\
\hline HDL-C & -5.4478 & $<0.001$ & -5.8256 & $<0.001$ & -5.6042 & $<0.001$ & -5.7035 & $<0.001$ \\
\hline Age & 5.6874 & $<0.001$ & 5.7798 & $<0.001$ & 5.6814 & $<0.001$ & 5.5263 & $<0.001$ \\
\hline Female & -4.5793 & 0.290 & -3.6519 & 0.408 & -3.4003 & 0.441 & -3.1102 & 0.482 \\
\hline Family history of diabetes & -0.5470 & 0.826 & -0.4996 & 0.840 & -0.3766 & 0.879 & -0.6020 & 0.809 \\
\hline Body mass index & 1.9748 & 0.412 & 2.0505 & 0.395 & 2.7796 & 0.259 & 2.6613 & 0.284 \\
\hline Baseline IAF & -18.3480 & $<0.001$ & -18.4851 & $<0.001$ & -18.7874 & $<0.001$ & -18.7021 & $<0.001$ \\
\hline Baseline abdominal SCF & 1.3502 & 0.512 & 1.3385 & 0.515 & 1.1189 & 0.587 & 1.1014 & 0.596 \\
\hline Baseline thigh SCF & 1.2272 & 0.510 & 1.3047 & 0.484 & 0.8375 & 0.657 & 0.9188 & 0.627 \\
\hline Change in body weight from baseline to 5 years & 14.0051 & $<0.001$ & 14.0129 & $<0.001$ & 14.1464 & $<0.001$ & 14.0943 & $<0.001$ \\
\hline Baseline 2-hour OGTT BLG & 7.9810 & 0.038 & 8.2312 & 0.033 & 7.9498 & 0.039 & 7.4957 & 0.053 \\
\hline HOMA-IR & 1.3593 & 0.625 & 1.2584 & 0.651 & 0.9991 & 0.720 & 1.0695 & 0.701 \\
\hline Alcohol consumption & & & 1.4078 & 0.297 & 1.3693 & 0.310 & 1.2828 & 0.357 \\
\hline Physical activity & & & & & -1.5779 & 0.160 & -1.6483 & 0.147 \\
\hline Current smoker & & & & & & & -2.4761 & 0.505 \\
\hline R squared & & 0.4004 & & 0.4022 & & 0.4054 & & 0.4074 \\
\hline
\end{tabular}

IAF, intra-abdominal fat; HDL-C, high-density lipoprotein cholesterol; SCF, subcutaneous fat; OGTT, oral glucose tolerance test; BLG, blood glucose; HOMA-IR, homeostasis model assessment of insulin resistance. 
associated with HDL-C [42]. However, the only measure of physical activity available to us came from a baseline questionnaire that might not have fully reflected participants' energy expenditure during the follow-up period. Despite these limitations, we believe that this is the first prospective study indicating that it may be possible to predict change in IAF measured by imaging using HDL-C.

In conclusion, HDL-C was significantly related to the accumulation of IAF in Japanese-Americans. The findings of this longitudinal analysis present novel evidence supporting the hypothesis that HDL-C or a correlate may contribute to the accumulation of IAF.

\section{CONFLICTS OF INTEREST}

No potential conflict of interest relevant to this article was reported.

\section{ACKNOWLEDGMENTS}

We appreciate the King County Japanese-American community for support and help. We also thank the support of VA Puget Sound for allowing Edward J. Boyko and Steven E. Kahn to participate in this research. Some of the data were presented as an abstract at the 79th ADA Annual Meeting in 2019.

This work was supported by National Institutes of Health grants DK-31170 and HL-49293; facilities and services provided by the Diabetes Research Center (DK-017047), Clinical Nutrition Research Unit (DK-035816), and the General Clinical Research Center (RR-000037) at the University of Washington. The funding entities had no role in the conduct of this study or interpretation of its results.

\section{AUTHOR CONTRIBUTIONS}

Conception or design: S.O.S., W.Y.F., E.J.B. Acquisition, analysis, or interpretation of data: S.O.S., Y.C.H., H.U.R., D.L.L., W.Y.F., E.J.B. Drafting the work or revising: S.O.S., H.U.R., S.E.K., W.Y.F., E.J.B. Final approval of the manuscript: S.O.S., Y.C.H., S.E.K., W.Y.F., E.J.B.

\section{ORCID}

Sun Ok Song https://orcid.org/0000-0003-4829-3407

\section{REFERENCES}

1. Elffers TW, de Mutsert R, Lamb HJ, de Roos A, Willems van Dijk K, Rosendaal FR, et al. Body fat distribution, in particular visceral fat, is associated with cardiometabolic risk factors in obese women. PLoS One 2017;12:e0185403.

2. Pouliot MC, Despres JP, Lemieux S, Moorjani S, Bouchard $\mathrm{C}$, Tremblay A, et al. Waist circumference and abdominal sagittal diameter: best simple anthropometric indexes of abdominal visceral adipose tissue accumulation and related cardiovascular risk in men and women. Am J Cardiol 1994; 73:460-8.

3. Boyko EJ, Leonetti DL, Bergstrom RW, Newell-Morris L, Fujimoto WY. Visceral adiposity, fasting plasma insulin, and lipid and lipoprotein levels in Japanese Americans. Int J Obes Relat Metab Disord 1996;20:801-8.

4. McNeely MJ, Shofer JB, Leonetti DL, Fujimoto WY, Boyko EJ. Associations among visceral fat, all-cause mortality, and obesity-related mortality in Japanese Americans. Diabetes Care 2012;35:296-8.

5. Fujimoto WY, Bergstrom RW, Boyko EJ, Chen KW, Leonetti DL, Newell-Morris L, et al. Visceral adiposity and incident coronary heart disease in Japanese-American men. The 10year follow-up results of the Seattle Japanese-American Community Diabetes Study. Diabetes Care 1999;22:180812.

6. Hwang YC, Fujimoto WY, Hayashi T, Kahn SE, Leonetti DL, Boyko EJ. Increased visceral adipose tissue is an independent predictor for future development of atherogenic dyslipidemia. J Clin Endocrinol Metab 2016;101:678-85.

7. Montague CT, O'Rahilly S. The perils of portliness: causes and consequences of visceral adiposity. Diabetes 2000;49: 883-8.

8. Wander PL, Boyko EJ, Leonetti DL, McNeely MJ, Kahn SE, Fujimoto WY. Change in visceral adiposity independently predicts a greater risk of developing type 2 diabetes over 10 years in Japanese Americans. Diabetes Care 2013; 36:289-93.

9. Hwang YC, Hayashi T, Fujimoto WY, Kahn SE, Leonetti DL, McNeely MJ, et al. Visceral abdominal fat accumulation predicts the conversion of metabolically healthy obese subjects to an unhealthy phenotype. Int J Obes (Lond) 2015; 39:1365-70.

10. Oka R, Yagi K, Sakurai M, Nakamura K, Nagasawa SY, Miyamoto $\mathrm{S}$, et al. Impact of visceral adipose tissue and subcutaneous adipose tissue on insulin resistance in middle- 
aged Japanese. J Atheroscler Thromb 2012;19:814-22.

11. Hwang YC, Fujimoto WY, Kahn SE, Leonetti DL, Boyko EJ. Greater visceral abdominal fat is associated with a lower probability of conversion of prehypertension to normotension. J Hypertens 2017;35:1213-8.

12. Hirano T, Nohtomi K, Koba S, Muroi A, Ito Y. A simple and precise method for measuring HDL-cholesterol subfractions by a single precipitation followed by homogenous HDLcholesterol assay. J Lipid Res 2008;49:1130-6.

13. Gordon T, Castelli WP, Hjortland MC, Kannel WB, Dawber TR. High density lipoprotein as a protective factor against coronary heart disease. The Framingham Study. Am J Med 1977;62:707-14.

14. Mahdy Ali K, Wonnerth A, Huber K, Wojta J. Cardiovascular disease risk reduction by raising HDL cholesterol: current therapies and future opportunities. $\mathrm{Br} \mathrm{J}$ Pharmacol 2012; 167:1177-94.

15. Emerging Risk Factors Collaboration, Di Angelantonio E, Sarwar N, Perry P, Kaptoge S, Ray KK, et al. Major lipids, apolipoproteins, and risk of vascular disease. JAMA 2009; 302:1993-2000.

16. Miller NE, Thelle DS, Forde OH, Mjos OD. The Tromsø heart-study. High-density lipoprotein and coronary heart-disease: a prospective case-control study. Lancet 1977;1:965-8.

17. Gordon DJ, Knoke J, Probstfield JL, Superko R, Tyroler HA. High-density lipoprotein cholesterol and coronary heart disease in hypercholesterolemic men: the Lipid Research Clinics Coronary Primary Prevention Trial. Circulation 1986; 74:1217-25.

18. Rye KA, Barter PJ. Cardioprotective functions of HDLs. J Lipid Res 2014;55:168-79.

19. Valentino G, Bustamante MJ, Orellana L, Kramer V, Duran $\mathrm{S}$, Adasme $\mathrm{M}$, et al. Body fat and its relationship with clustering of cardiovascular risk factors. Nutr Hosp 2015;31: 2253-60.

20. Rashid S, Genest J. Effect of obesity on high-density lipoprotein metabolism. Obesity (Silver Spring) 2007;15:287588.

21. Yang Z, Ding X, Liu J, Duan P, Si L, Wan B, et al. Associations between anthropometric parameters and lipid profiles in Chinese individuals with age $\geq 40$ years and BMI $<28 \mathrm{~kg}$ / m2. PLoS One 2017;12:e0178343.

22. Ninic A, Spasojevic-Kalimanovska V, Bogavac-Stanojevic N, Kotur-Stevuljevic J, Kornic-Ristovski D, Stefanovic A, et al. Associations between anthropometric parameters and serum lipids in preadolescent and adolescent girls and boys.
Clin Lipidol 2015;10:119-28.

23. Fujimoto WY, Leonetti DL, Kinyoun JL, Shuman WP, Stolov WC, Wahl PW. Prevalence of complications among second-generation Japanese-American men with diabetes, impaired glucose tolerance, or normal glucose tolerance. Diabetes 1987;36:730-9.

24. Fujimoto WY, Bergstrom RW, Leonetti DL, Newell-Morris LL, Shuman WP, Wahl PW. Metabolic and adipose risk factors for NIDDM and coronary disease in third-generation Japanese-American men and women with impaired glucose tolerance. Diabetologia 1994;37:524-32.

25. Paffenbarger RS Jr, Wing AL, Hyde RT. Physical activity as an index of heart attack risk in college alumni. Am J Epidemiol 1978;108:161-75.

26. Kuhns LR, Borlaza GS, Seigel R, Thornbury JR. External anatomic landmarks of the abdomen related to vertebral segments: applications in cross-sectional imaging. AJR Am J Roentgenol 1978;131:115-7.

27. Boyko EJ, Fujimoto WY, Leonetti DL, Newell-Morris L. Visceral adiposity and risk of type 2 diabetes: a prospective study among Japanese Americans. Diabetes Care 2000;23: 465-71.

28. Matthews DR, Hosker JP, Rudenski AS, Naylor BA, Treacher DF, Turner RC. Homeostasis model assessment: insulin resistance and beta-cell function from fasting plasma glucose and insulin concentrations in man. Diabetologia 1985;28:412-9.

29. Shuman WP, Morris LL, Leonetti DL, Wahl PW, Moceri VM, Moss AA, et al. Abnormal body fat distribution detected by computed tomography in diabetic men. Invest Radiol 1986;21:483-7.

30. Leenen R, van der Kooy K, Seidell JC, Deurenberg P. Visceral fat accumulation measured by magnetic resonance imaging in relation to serum lipids in obese men and women. Atherosclerosis 1992;94:171-81.

31. Lupattelli G, Pirro M, Mannarino MR, Siepi D, Roscini AR, Schillaci G, et al. Visceral fat positively correlates with cholesterol synthesis in dyslipidaemic patients. Eur J Clin Invest 2012;42:164-70.

32. Luo Y, Ma X, Shen Y, Hao Y, Hu Y, Xiao Y, et al. Positive relationship between serum low-density lipoprotein cholesterol levels and visceral fat in a Chinese nondiabetic population. PLoS One 2014;9:e112715.

33. Yildirim B, Sabir N, Kaleli B. Relation of intra-abdominal fat distribution to metabolic disorders in nonobese patients with polycystic ovary syndrome. Fertil Steril 2003;79:1358- 
64.

34. Song SO, Hwang YC, Kahn SE, Leonetti DL, Fujimoto WY, Boyko EJ. Intra-abdominal fat and high density lipoprotein cholesterol are associated in a non-linear pattern in Japanese-Americans. Diabetes Metab J 2020;44:277-85.

35. Couillard C, Despres JP, Lamarche B, Bergeron J, Gagnon J, Leon AS, et al. Effects of endurance exercise training on plasma HDL cholesterol levels depend on levels of triglycerides: evidence from men of the Health, Risk Factors, Exercise Training and Genetics (HERITAGE) Family Study. Arterioscler Thromb Vasc Biol 2001;21:1226-32.

36. Rader DJ. Regulation of reverse cholesterol transport and clinical implications. Am J Cardiol 2003;92:42J-9J.

37. Zhao SP, Yang J, Li J, Dong SZ, Wu ZH. Effect of niacin on LXRalpha and PPARgamma expression and HDL-induced cholesterol efflux in adipocytes of hypercholesterolemic rabbits. Int J Cardiol 2008;124:172-8.

38. Wei H, Averill MM, McMillen TS, Dastvan F, Mitra P, Subramanian S, et al. Modulation of adipose tissue lipolysis and body weight by high-density lipoproteins in mice. Nutr Diabetes 2014;4:e108

39. Hosseini B, Mirzaei K, Maghbooli Z, Keshavarz SA, Hossein-Nezhad A. Compare the resting metabolic rate status in the healthy metabolically obese with the unhealthy metabolically obese participants. J Nutr Intermed Metab 2016;6:4853.

40. Kazumi T, Kawaguchi A, Hirano T, Yoshino G. Serum adiponectin is associated with high-density lipoprotein cholesterol, triglycerides, and low-density lipoprotein particle size in young healthy men. Metabolism 2004;53:589-93.

41. Han SJ, Boyko EJ, Fujimoto WY, Kahn SE, Leonetti DL. Low plasma adiponectin concentrations predict increases in visceral adiposity and insulin resistance. J Clin Endocrinol Metab 2017;102:4626-33.

42. Kokkinos PF, Fernhall B. Physical activity and high density lipoprotein cholesterol levels: what is the relationship? Sports Med 1999;28:307-14. 